\title{
ITINERÁRIO PARA DESCONSTRUÇÃO DO INSTITUTO PSIQUIÁTRICO FORENSE DO RIO GRANDE DO SUL
}

\author{
ITINERARY FOR DECONSTRUCTION OF THE FORENSIC \\ PSYCHIATRIC INSTITUTE OF RIO GRANDE DO SUL
}

Claudemir José Ceolin Missagia. Itinerário para desconstrução do instituto psiquiátrico forense do Rio Grande do Sul. Rev Bras Crescimento Desenvolv Hum. 2010; 20(1): 129-137

\begin{abstract}
Resumo:
Este estudo tem como objetivo descrever a experiência das reformas psiquiátricas, as medidas de humanização e as medidas de desospitalização. A primeira reforma psiquiátrica nasceu da ideia de recuperação pelo trabalho. Mas com o passar do tempo, estas colônias se mostraram iguais aos asilos tradicionais. Do modo como o Código Penal brasileiro disciplina o assunto é muito fácil a violação do princípio da proporcionalidade na medida em que o autor de um furto e de lesões corporais, p. ex., pode ficar privado de sua liberdade (ou ter sua liberdade restringida) por tempo igual ou superior ao autor de um homicídio, de um roubo ou de um estupro. Na medida em que fui decretando as extinções das medidas de segurança percebi que, por seu grande número, não podia deixar a cargo somente do Instituto Psiquiátrico Forense as desinstitucionalizações. Assim, foi oficiadoàs autoridades para receber os pacientes do Instituto Psiquiátrico Forense do Estado. Cabe aos magistrados, convocar o direito a ser, como categoria ética e não apenas como categoria científica, como a salvaguarda dos outros contra minhas possíveis deserções, sendo que a magistratura não deve e não pode sacrificar o Direito no altar do Poder e Estado.
\end{abstract}

Palavras-chave: direito penal; psiquiatria; executoriedade da lei.

\begin{abstract}
:
This study aims to describe the experience of psychiatric reforms, measures of humanization and measures of deinstitutionalization. The first psychiatric reform was the idea of the recovery throutgh work. But over time, these colonies showed the same as traditional asylums. The way the Brazilian Penal Code regulates the subject is very easy to violate the principle of proportionality in that the perpetrator of a robbery and bodily injury, for example, may be deprived of his/her liberty (or have his freedom restricted) for an equal or greater sentence than the author of a murder, a robbery or a rape. To the extent I was enacting the extinctions of the security measures I realized that, by their large numbers could not be borne only of the Forensic Psychiatric Institute. I decided to request officially the authorities to receive patients from the Forensic Psychiatric Institute of the State. Officers of the Governor, the Human Rights Commissions of the Legislative Assembly and OAB / RS, the health authority and state and municipal prosecutor for the Defense of Human Rights and Citizenship prosecutors, etc. Finally, I leave one last message. Especially, we judges, shall call a right to be as ethical category and not just scientific category, the true and beautiful words of BALLESTEROS "the protection of others against my possible defections" and, as highlighted by this author, now in this true and beautiful words, the judiciary should not and cannot sacrifice the law on the altar of power and state.
\end{abstract}

Key words: criminal law; psychiatry; law enforcement.

1 Juiz de Direito do Tribunal de Justiça do Rio Grande do Sul.

Correspondência para: cmissaggia@tj.rs.gov.br 


\section{INTRODUÇÃO}

O exercício da Magistratura, na condição de juiz de direito, que jurisdiciono o único manicômio ${ }^{1}$ (ou hospital psiquiátrico) deste Estado do Rio Grande do Sul..

Desta maneira, faz-se necessário uma descontrução, a partir do interior do manicômio, com vistas ao seu pleno funcionamento e reitegração dos indivíduos à sociedade.

O Instituto Psiquiátrico Forense contava com 719 processos e hoje tem 602. Em 2008 saíram 104 pessoas do Instituto Psiquiátrico Forense. O fluxo de clientes tem sido "negativo”, ou seja, estão saindo mais do que estão entrando.

A novidade da experiência, além de iniciar extramuros, é uma experiência de reforma psiquiátrica em um manicômio judiciário com iniciativa pela porta de saída. A Itália, que tem o melhor exemplo de reforma psiquiátrica, vem tocando apenas de leve nos manicômios judiciários.

\section{EXPERIÊNCIAS DAS REFORMAS PSIQUIÁTRICAS}

A primeira reforma psiquiátrica nasceu da ideia de recuperação pelo trabalho. Mas com o passar do tempo, estas colônias se mostraram iguais aos asilos tradicionais.

As experiências contemporâneas de reforma psiquiátrica, para efeito didático, serão divididas "em dois grupos mais um”.

O $1^{\circ}$ grupo, é composto pela Comunidade Terapêutica e pela Psicoterapia Insti- tucional. Os modelos do $1^{\circ}$ grupo apostavam que o fracasso estava na gestão do próprio hospital.

$\mathrm{O} 2^{\circ}$ grupo é formado pela Psiquiatria de Setor e Psiquiatria Preventiva. Estas experiências procuravam demonstrar que o modelo hospitalar estava esgotado, e que o mesmo deveria ser desmontado aos poucos, isto é, deveria ser tornado obsoleto a partir da construção de serviços assistenciais (hospitais-dia, oficinas terapêuticas, etc. No outro grupo, estão a Antipsiquiatria e a Psiquiatria Democrática. Ambas consideram que a questão mesma estaria no modelo colocado em xeque, assim como suas instituições assistenciais. ${ }^{1}$

\section{DAS MEDIDAS DE HUMANIZAÇÃO}

Consciente dos estigmas, da falta de dignidade e da cidadania castrada - pontuado pelas raízes histórico-filosóficas - das práticas na desconstrução dos manicômios desde Franco Basagliab, passei a tomar algumas decisões: 1) Editei as Ordens Normativas para que a Direção do Instituto:

a) nomeasse imediatamente uma Equipe Técnica multidisciplinar (psiquiatra, psicóloga e assistente social), que deveria elaborar um "plano terapêutico", desde o início da entrada do paciente no Instituto Psiquiátrico Forense;

b) informasse as razões pelas quais um paciente fosse transferido para Unidade Fechada ou para o isolamento ${ }^{\text {; }}$

c) informasse o remédio e a dosagem, bem como se o paciente apresentava proble-

b A Instituição Negada. $3^{\text {a }}$ edição. Tradução de Heloisa Jahn. Graal, Rio de Janeiro, 2001; Escritos Selecionados. Organização Paulo Amarante. Tradução Joana Angélica d”Ávila Melo. Garamond, Rio de Janeiro, 2005.

c J.A.. permaneceu em coma irreversível por 5 meses e depois faleceu por ter sido agredido por outro paciente. O PEC já estava extinto e já havia a possibilidade de paciente do paciente para Alegrete ou Uruguaiana, quando este desorganizou-se e foi internado numa Unidade Fechada com outros pacientes. Uma verdadeira imprudência, pois este paciente já com a medida de segurança prescrita, deveria ser colocado no isolamento, nos denominados “quartos de cuidado”. Tlavez esta história nos traga bons ensinamentos: quando a instituição total é o único ponto de referência é porque a rede realmente apresenta falhas. 
mas clínicos e quais eram as providências que estavam sendo tomadas;

d) informasse quais os pacientes internos têm direito à remição pelo trabalho e pelo estudo, com base no art. 126, § $1^{\circ}$ da LEP;

e) autorizei aos pacientes das Unidades "F" e "G" que saíssem ao pátio em pequeno grupo na ocasião da eclosão do esgoto;

f) constatando que os doentes ficavam contidos em camas de concreto doei seis (6) leitos hospitalares ao Instituto Psiquiátrico Forense com o dinheiro arrecadado com as penas de prestação pecuniária e determinei a destruição daquelas camas.

Como magistrado não poderia ir além.

Dizia-se que o juiz só faltava "dormir" no Instituto Psiquiátrico Forense, no intuito de enfraquecer minha autoridade, típico de uma instituição que, invadida por ventos democráticos e humanitários, busca obstruir nosso trabalho, algumas vezes abertamente, outras vezes de forma muito sutil, mas esta de forma permanente.

É evidente que, diante da grandeza do desafio não poderíamos ser ingênuos. Desde Foucault ${ }^{2}$ sabemos que os poderes moleculares se expandem por toda a sociedade (e não se confundem, necessariamente, com os aparelhos estatais) e, por conseguinte, em se tratando de uma instituição total de caráter público, já octogenária, compreendemos que a tarefa seria mais árdua ainda, por isso recorremos a alguns mecanismos, por exemplo, um controle estatístico de cada medida de segurança, porque a PROCERGS não oferece isto, determinei a extração de cópias dos autos para formação do Procedimento Administrativo para controlar aqueles pacientes que já tiveram alta.
Isto no âmbito do gabinete, pois o Grupo Trabalho merece um título a parte. Pensei isto para também me proteger.

\section{MEDIDAS DE DESOSPITALIZAÇÃO}

Foram decretados 238 processos com base nas seguintes razões:
a) prescrição;
b) proporcionalidade;
c) indulto;
d) ausência de periculosidade.

As extinções com base na (a.1) prescrição tem assento constitucional tendo, de outra parte, parcial acolhida pela jurisprudência do Supremo Tribunal Federal. Tenho decretado a prescrição pela máxima in abstractu (art. 109 do Código Penal), embora meu entendimento seja, de fato, pela pena mínima in abstractu.

Decretei a extinção de 159 processos com base na prescrição.

Foram encontrados 54 (cinquenta e quatro) processos com internos há mais de 20 anos, $\mathbf{1 5}$ (quinze) internos há mais de 15 anos e 02 (dois) internos há mais de 40 anos.

Postulado básico do Direito, e em especial do Direito Penal, é o (b.2) princípio da proporcionalidade $^{\mathrm{d}, \mathrm{e}, \mathrm{f}, \mathrm{g}, \mathrm{h}}$ pertencente à Dogmática Jurídica, que vale para as infrações de menor potencial ofensivo.

Foi decretado a extinção de 8 processos com base no princípio da proporcionalidade, isso em primeira decisão.

Encontrou-se 66 (sessenta e seis) PECs de crimes de baixa potencialidade lesiva (dados atualizados até 30/09/2008).

d Correia, José Manuel Sérvulo. Legalidade e autonomia contratual nos contratos administrativos. Coimbra, Editora Almedina, 1987, p. 114.

e Dias, Jorge de Figueiredo. Direito Penal Português. As Consequências Jurídicas do Crime. Coimbra, Coimbra Editora, p. 4489.

f Monteiro, Cristina Líbano. Perigosidade de Inimputáveis e “In Dubio Pro Reo”. Coimbra, Coimbra Editora, pp. 166-7.

g Ávila, Humberto Bergmann. A distinção entre princípios e regras e a redefinição do dever de proporcionalidade. Revista de Direito Administrativo. Rio de Janeiro, Editora Renovar, (215):173-4, 1999.

h Santos, Juarez Cirino dos. Teoria da Pena: Fundamentos políticos e Aplicação judicial. Curitiba:LumenIures, 2005, pp. 192-3. 
Dentre eles 6 contravenções ${ }^{\mathrm{i}}$ (internos com 26 anos, 6 meses e 19 dias e 17 anos, 2 meses e 14 dias); 32 lesões corporais, duas tentativas de furto simples, várias invasões de domicílio, ameaças, desacatos, danos, etc.

Quase todos estes crimes são de lesão corporal leve, ou seja, na sua maioria, com pena máxima 1 ano de detenção. Em 16 casos, os pacientes estavam internados há mais de 16 anos; em 2 casos há mais de 30 anos, e em 25 há mais de 10 anos.

Especificamente, quanto à Medida de Segurança, pondera Luiz Flávio Gomesi4:

Do modo como o Código Penal brasileiro disciplina o assunto é muito fácil a violação do princípio da proporcionalidade na medida em que o autor de um furto e de lesões corporais, p. ex., pode ficar privado de sua liberdade (ou ter sua liberdade restringida) por tempo igual ou superior ao autor de um homicídio, de um roubo ou de um estupro.

\section{$O$ (3) indulto natalino.}

Pela $1^{\text {a }}$ vez no país foi editado um decreto de indulto para aqueles que tenham sofrido privação da liberdade, internação ou tratamento ambulatorial por período igual ou superior ao máximo da pena cominada à infração penal.

A diferença entre a prescrição e o indulto é a de que este abrevia o prazo de internamento. Por exemplo, no crime de lesão corporal leve, o máximo da pena é de 1 ano de detenção e a prescrição é de 4 anos. $O$ indulto deverá ser decretado em 1 ano e a prescrição, poderá ser decretada em 4 anos.

Decretei a extinção de 67 medida de segurança com base no indulto.
A (4) ausência de periculosidade, que é pressuposto tanto para o processo de conhecimento, como para o processo de execução, é demonstrada por vários pacientes que havia anos não cometem crime algum, ou decorrentes das conclusões dos próprios psiquiatras afirmando que o caso é mais "social do que psiquiátrico", que o paciente poderia "ser beneficiado com tratamentos oferecidos por outras instituições do tipo albergues ou pensões protegidas, onde o enfoque fosse centralizado em atividades ocupacionais supervisionadas", que o paciente "não apresenta periculosidade social, desde que em tratamento e em uma instituição protegida”, enfim, que o paciente tem que permanecer no IPF, "porque não foram criados os serviços substitutivos da Lei da Reforma Psiquiátrica”, etc.

Mas os peritos opinam que estes pacientes devem continuar no Instituto Psiquiátrico Forense, porque permanece sua periculosidade.

Usam locuções como determinante familiar (ausência da família), determinante biológico (doenças tais como esquizofrenia, que não tem perspectiva aparente de cura, quando na verdade existem milhares de esquizofrênicos além dos muros) ou determinante psicológico (pacientes que não cumprem as regras da instituição, são alcoólatras ou drogadictos) como álibi para sustentar o conceito de periculosidade.

Quanto isto ocorre não há desculpa para deixar o paciente, há a possibilidade de colocação em pensões protegidas, residenciais terapêuticas, CAPS, etc.

Segundo Robert Castel ${ }^{\mathrm{k} 5}$ :

"um risco não resulta da presença de um perigo preciso, trazido por uma pessoa ou um grupo de indivíduo, mas da

i Exemplos para escandalizar: um paciente tinha cometido contravenção penal de pertubação da tranquilidade, estava no Instituto Psiquiátrico Forense há 26 anos, 6 meses e 19 dias e um paciente que havia praticado vias de fato estava lá há 17 anos, 2 meses e 24 dias.

j $\quad$ Duração das Medidas de Segurança. Revista dos Tribunais, ano 8 - janeiro de 1991, vol. 663, p. 263.

k A Gestão dos Riscos. Da Antipsiquiatria à Pós-Psicanalise. Tradução Celina Luz. Rio de Janeiro, 1987, p. 1125. 
colocação em relação de dados gerais impessoais ou fatores (de riscos) que tornaram mais ou menos provável o aparecimento de comportamento indesejáveis”.

Assim, para o Autor o fundamental é vigiar, quer dizer, se colocando em posição de antecipar a emergência de acontecimentos indesejáveis (doenças, anomalias, comportamentos de desvio, atos de delinquência, etc.) no seio das populações portadores de algum tipo de risco.

Segundo Boaventura de Souza Santos (Visão, janeiro de 2001, A Ciência e O Risco Social) a humanidade sempre conviveu com o risco, o que mudou, ao longo dos séculos foram os tipos de "riscos" e a capacidade de lhes prevenir ou minimizar as consequências. Argumenta que "nos últimos duzentos anos, à medida que se caminhando para 'uma sociedade completamente administrada', a produção do risco e proteção contra ele, foram-se vinculando mais uma à outra".

O fator de risco ou risco social (periculosidade social), determinantes "familiar", "biológico" ou "psicológico", como costumam designar os psiquiatras em seus laudos, locuções que, por sua abrangência e latitude tem uma carga maior, pois pode significar que a pessoa não possa sair do manicômio devido a fatos indesejáveis.

Mas digamos que estas assertivas tem algum resquício de cientificidade.

Para exemplificar, em janeiro deste ano (2009), estava no Instituto Psiquiátrico Forense para uma reunião semanal do GRUPO DE TRABALHO, e fiquei sabendo que há 2 (dois) dias faltava papel higiênico para uso dos internos. Exigi, naquele exato momento, que a Administração providenciasse o papel higiênico; nas Unidades Fechadas, cujos banheiros não tem portas, o que obriga os internos a fazerem suas necessidades na frente uns dos outros. Não havia remédio suficiente e os "surtados" eram isolados em quartos em que havia camas de concreto. Doei com as verbas das penas pecuniárias 6 camas e determinei a destruição daquelas.

Ora, como dá para perceber, o determinante "biológico" ou "psicológico", nestas condições, associado à falta de remédio histórica no Instituto Psiquiátrico Forense, e sem uma privacidade elementar, restará prejudicado (são noções ligadas ao "risco social”).

Por esses fatos, que se adivinham corriqueiros ao ponto da banalização é que as instituições totais são "processos de mortificação do eu", como disse Erving Goffmann. ${ }^{6}$

O atual Código Penal espanhol, aprovado em 23/11/1995, fez uma distinção entre periculosidade criminal e periculosidade social. A lei agora exige que aja da probabilidade de prática de delitos e não mais de fatos indesejáveis, ou não mais de uma estrutura familiar que lhe dê suporte. Periculosidade social é a que os psiquiatras e os juízes definem nos casos concretos sem vinculação alguma com bens penalmente tuteláveis. Maria Florência Hegglin $^{1^{7}}$ salienta que esta acepção vulnera o princípio da legalidade. A periculosidade, então, se porventura existente, é individual, do sujeito ou não se caracteriza e deve ser demonstrada cabalmente em delicado juízo de prognose.

A periculosidade, mesmo a criminal como exige o Código Penal espanhol, não é um conceito rigorosamente científico. Castel argumenta que a "periculosidade" é uma noção misteriosa, qualidade inerente a um sujeito e só se caracteriza a posteriori, ou seja, após a prática do fato indesejável (sentido lato sensu) ${ }^{\mathrm{m}}$. Mas adverte que a noção de indivíduo 'perigoso', tem como pressuposto um jul-

1 Los Enfermos Mentales em el Derecho Penal. Buenos Aires, Editores Del Puerto, 2006, p. 94. m Idem, p. 126. 
gamento substancialista, e significa "chances mais ou menos fortes de que exista uma correlação entre tais sintomas e tal ato futuro". " Noutra passagem, Castel diz que "Em termos de lógica, o diagnóstico de periculosidade abate a categoria do possível sobre a do real, sob o pretexto de que o possível é - mais ou menos - provável”. ${ }^{\circ}$ Explica o Autor que a impotência da psiquiatria a objetivar completamente a noção de periculosidade foi pesada de carregar.

Onde se encontra, então, o juízo de prognose da periculosidade?

Denise Dias Barros ${ }^{8}$ refere que a medicina vinculou a doença mental à periculosidade e, assim, por conseguinte, o doente mental era incurável ou irrecuperável e imprevisível, no sentido de ser perigoso. Doença mental não se confunde com periculosidade.

Não se pode confundir periculosidade com agitação psicomotora (surto). Nestes casos, o doente mental deve ser contido fisicamente evitando a auto-lesão e agressão a terceiros.

A noção de periculosidade é um conceito que se sobrepõe à ideia de cuidado e autonomia. A periculosidade não é noção de um Estado de direito que se pretenda garantista e progressista. Também as noções e teses de que é preciso prender para proteger remontam ao Estado de Polícia e violam o Estado de Direito.

Por outro lado, ainda se tido por cognoscível, científico, o conceito de periculosidade, ele é indispensável no momento da aplicação e também no decorrer do processo de execução da medida de segurança. ${ }^{\mathrm{p}}$

O Tribunal Europeu dos Direitos Humanos “destacou, em 24 de setembro de 1992, que a 'situação de vulnerabilidade' e impotência que caracteriza os pacientes internados em um hospital psiquiátrico exige uma maior vigilância no que se refere ao controle do respeito ao Convênio (...)". q

Pelo nosso levantamento, são 80 casos de ausência de periculosidade (dados de 30/ 09/2008). Decretei em 19 casos a extinção da medida de segurança pela ausência de periculosidade. ${ }^{\mathrm{r}}$

Um paciente esteve internado no Instituto Psiquiátrico Forense, até o decreto de extinção da medida de segurança pela prescrição, aproximadamente $\mathbf{4 3}$ anos. Durante todo esse tempo, apenas os 3 (três) primeiros laudos atestavam a periculosidade deste paciente. Havia um paciente que estava internado há 49 anos e quando meu assessor terminou o relatório, aportou nos autos a certidão de óbito.

Mas quando o Tribunal de Justiça reformava as decisões de prescrição, eu proferia uma segunda decisão de extinção com base na ausência de periculosidade ou com no princípio da proporcionalidade, conforme o caso, o que rendeu um processo disciplinar. Graças ao apoio de alguns colegas fui absolvido à unanimidade.

\section{DA CONSTITUIÇÃO DO GRUPO DE TRABALHO E O PROCEDIMENTO DE DESINSTITUCIONALIZAÇÃO}

$\mathrm{Na}$ medida em fui decretando as extinções das medidas de segurança percebi que, por seu grande número, não podia deixar a cargo somente do Instituto Psiquiátrico Forense as desinstitucionalizações. Resolvi, en-

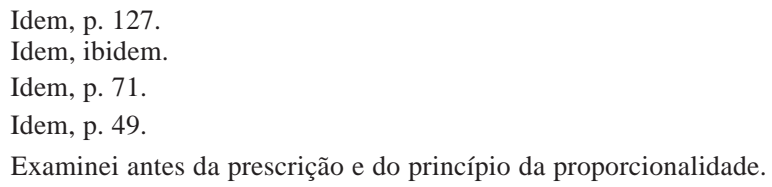


tão, oficiar às autoridades para receber os pacientes do Instituto Psiquiátrico Forense do Estado. Oficiei à Governadora, as Comissões de Direitos Humanos da Assembleia Legislativa e da OAB/RS, a autoridade sanitária estadual e municipal e a Promotoria de Defesa da Cidadania e Direitos Humanos do Ministério Público, etc.

Este GRUPO DE TRABALHO, criado em 12/09/2007 por um Inquérito Civil Público instaurado pela Promotora de Justiça da Cidadania e dos Direitos Humanos Ângela Salton Rotunno, se reúne todas as quintas-feiras no Instituto Psiquiátrico Forense, do qual participo, para discutir e avaliar caso por caso num verdadeiro trabalho artesanal, GRUPO DE TRABALHO que cada vez mantêm o grupo em movimento, grupo este que vem crescendo em componentes e em parceiros.

Nas medidas de segurança, por mim extintas, fixo um prazo de prazo de 120 (cento e vinte) dias para o Grupo de Trabalho interinstitucional e para o IPF, por sua equipe multidisciplinar, “aprontem” os pacientes para processo de desospitalização, que tem como prazo máximo 1 (um) ano.

Este GRUPO DE TRABALHO, que presta contas mensais à Promotoria de Justiça, que instaurou o inquérito civil, colabora com a equipe do Instituto Psiquiátrico Forense no sentido de discutir minuciosamente os casos e encaminhar o paciente a uma pensão protegida, CAPS das respectivas regiões quando for caso, do benefício de "Volta para casa" e do LOAS, etc. Estes benefícios tem sido fundamentais para desospitalização.

O GRUPO DE TRABALHO autodeno-minou-se de Qorpo Santo, nome escolhido para homenagem o dramaturgo e poeta gaúcho José Joaquim Campos Leão (1829/1883), portador de sofrimento psíquico, que produziu uma extensa obra literária. Interditado, lutou para reaver seus direitos civis e obteve êxito em fazer valer sua palavra. Teve sua obra reconhecida qua- se cem anos depois, sendo considerado um dos precursores do teatro do absurdo e da poesia moderna.

\section{DO TERMO DE AJUSTE DECONDUTA}

Diante da realidade encontrada no atendimento ao paciente em Medida de Segurança, fiz as tratativas da formulação do Termo de Ajustamento de Conduta (TAC), proposto pela Promotoria de Justiça de Controle e de Execução Criminal (Dra. Cynthia Jappur) e pela Promotoria de Justiça de Defesa dos Direitos Humanos, (Dra. Ângela Salton Rotunno), tendo um dos principais articuladores o Dr. Paulo Zietlow, Superintendente à época, que contempla os seguintes pontos:

- Regulamenta a contenção física e isolamento dos pacientes, adequando o IPF às mesmas exigências feitas aos hospitais psiquiátricos, inclusive proibindo o uso de algemas de metal.

- Prevê a construção de Residencial Terapêutico para pacientes em processo de desligamento do IPF.

- Prevê a contratação de 24 médicos psiquiatras, 40 técnicos em enfermagem, 7 médicos clínicos, 7 assistentes sociais, 8 psicólogos, 7 terapeutas ocupacionais, 3 enfermeiros e 1 farmacêutico.

- Prevê reformas nas instalações do IPF.

- Regulamenta a rotina para compra de medicação evitando interrupção no fornecimento de remédios.

- Estipula rotina para estimativa de gastos com material de higiene, devendo o Estado fornecer este material aos pacientes.

Já foram contratados psicólogos e assistentes sociais, e para o restante do quadro, que demanda concurso foi recentemente aberto edital para contra contratação emergencial. 
Mas mesmo depois do TAC continua faltando remédios, o me levou a representar para o Ministério Público.

\section{ALGUMAS DIFICULDADES E HORIZONTES QUE SE DESCORTINAM}

\section{1) Transinstitucionalização $0^{\mathrm{s}}$}

O GT, quando não há alternativa, especialmente nas hipóteses em já esteja caracterizado o hospitalismo, normalmente quanto às pessoas de mais idade e que não tem família, e em último caso encaminha os internos do Instituto Psiquiátrico Forense para outras instituições também fechadas. Mas procuraremos evitar que a "desinstitucionalização, portanto, entendida e praticada como desospitalização" produza, como diz Rotelli ${ }^{9}$, o abandono dos internos pelo mecanismo de um controle judicial.

\section{2) Censo}

A Doutora Maria Gabriela Curubeto Godoy formatou um "projeto de pesquisa” para os usuários do Instituto Psiquiátrico Forense. Este projeto pretende realizar um censo para conhecer a situação clínica, psicossocial e jurídica da população em cumprimento de Medida de Segurança vinculada ao Instituto Psiquiátrico Forense Doutor Maurício Cardoso (IPF-RS), único Hospital de Custódia e Tratamento do Rio Grande do Sul e maior manicômio judiciário do Brasil. A verba já foi empenhada pelo Ministério da Saúde, com a contrapartida do Secretaria da Saúde do Estado.

\section{3) Cultura e loucura}

A proposta é trazer, ou levar, para dentro da universidade (Departamento de Difusão Cultural da UFGRS, VEPMA - Setor de Psicologia - Pensão Protegida e CAIS) o tema da loucura e da medida de segurança, tentando incluir os pacientes e também os diversos cursos da universidade. Em 2010 a ênfase será na percussão. Os pacientes participariam em 3 momentos: antes de cada espetáculo, uma atividade de preparação e contextualização; os pacientes assistirão o espetáculo e no dia seguinte poderiam participar de uma conversa com os artistas, que usualmente acontece dentro do Projeto UNIMUSICA.

Está previsto também um ciclo de filmes com debates.

\section{CONSIDERAÇÕES FINAIS}

Conclama-se aos magistrados do interior e da Capital para que, na medida do possível, encaminhem os doentes mentais à rede de saúde pública de suas Comarcas ou respectivas $\mathrm{Ci}$ dades ou pelo menos que se avalie a concessão da alta progressiva, com a sentença condenatória, funcionando como uma "porta de entrada” (Portaria No 1.899, de 11 de setembro de 2008 do Ministério da Saúde). Devem ser evitados, a todo custo, a cronificação ou hospitalismo do sujeitot, gerados pela experiência de viver na dependência do hospital.

Encaminhar doentes mentais para condições absurdamente hostis, como eu acabo de relatar, é assinar quase uma prisão perpétua.

Aos sujeitos, pacientes do manicômio, deve ser proporcionado um certo grau de autonomia, até porque a autonomia no sentido kantiano, depois de Freud e Marx, não mais existe. Temos que evitar a transinstitucionalização.

Por fim, deixo uma última mensagem. Especialmente, a nós magistrados, cabe con-

Rotelli, Franco et ali. $2^{a}$ Edição. Editora Hucitec. São Paulo, 2001, p.21.

t Cronificação e hospitalismo são sintomas adquiridos nas dependências dos hospitais psiquiátricos: levados a necessidade de sobreviver o paciente se adapta ao ambiente alienante, recusando a possibilidade de viver fora da internação. 
vocar o direito a ser, como categoria ética e não apenas como categoria cientifica, nas verdadeiras e belas palavras de Ballesteros "a salvaguarda dos outros contra minhas possíveis

\section{REFERÈNCIAS}

1. Amarante, Paulo. Saúde mental e Atenção Psicossocial. Rio de Janeiro, Fiocruz, 2007.

2. Foucault, Michel. Microfísica do Poder. $24^{a}$ Edição. Rio de Janeiro: Edições Graal, 1979.

3. Basaglia, Franco. A Instituição Negada. $3^{a}$ edição. Tradução de Heloisa Jahn. Graal, Rio de Janeiro, 2001.

4. Gomes, Luiz Flávio. Duração das Medidas de Segurança. Revista dos Tribunais,

5. Castel, Robert. A Gestão dos Riscos. Da Antipsiquiatria à Pós-Psicanalise. Tradução Celina Luz. Rio de Janeiro, 1987.

6. Goffmann, Erving. Manicômios, Prisões e Conventos. \{Tradução Dante Moreira Leite\}. São Paulo, Perspectiva, 2007. deserções”"10, e, como destaca este Autor, agora nas suas verdadeira e belas palavras, a magistratura não deve e não pode sacrificar o Direito no altar do Poder e Estado.

7. Hegglin, Maria Florência. Los Enfermos Mentales em el Derecho Penal. Buenos Aires, Editores Del Puerto, 2006.

8. Barros, Denise Dias. Psiquiatria Social e Reforma Psiquiátrica. Paulo Amarante (org.). Rio de Janeiro: Editora Fiocruz,1994.

8. Dias, Jorge de Figueiredo. Direito Penal Português. As Consequências Jurídicas do Crime. Coimbra, Coimbra Editora.

9. Rotelli, Franco et ali. $2^{\circ}$ Edição. Editora Hucitec. São Paulo, 2001.

10. Neves, Antonio Castanheira. Escritos acerca do Direito, do Pensamento Jurídico, da sua Metodologia e Outros. VOLUME $2^{\circ}$. Coimbra, Coimbra Editora, 1995.

Recebido em 29 de setembro de 2009. Modificado em 02 de janeiro de 2010. Aceito em 30 de janeiro de 2010. 